\title{
A Remote Engineering Lab for Collaborative Experimentation
}

\author{
http://dx.doi.org/10.3991/ijoe.v9i3.2500 \\ Salaheddin Odeh ${ }^{1}$, Eiman Ketaneh ${ }^{2}$ \\ ${ }^{1}$ Al-Quds University, Abu Deis, Jerusalem, Palestinian Territories \\ ${ }^{2}$ Al-Quds Open University, Tulkarm, Palestinian Territories
}

\begin{abstract}
Collaborative working is a fundamental feature of contemporary organizations and is increasingly being supported by technology. Its main goal is to enable each of the collaborating group members to bring and to contribute ideas and knowledge to the group and then to share it with them in order to combine it into a final result. In engineering education, concepts taught through lectures are often complemented by lab experimentation, through which students can observe phenomena that are often difficult to explain by written material. This contribution presents a collaborative working environment for remote experimentation, which allows two students or more to conduct remote experiments at the same time as a team. The lab can be accessed via Internet from any place and at any time, and enables the students to obtain an automated help by either a human tutor or a rule-based e-tutor.
\end{abstract}

Index Terms-Collaborative working; e-collaboration; remote labs; evaluation; multi-user environments

\section{INTRODUCTION}

The term "collaborate" means "to work". Literally, to collaborate means to "co-work" or work together. Light et al. [1] define collaboration more precisely as: "Collaboration is the process of two or more people working together toward a common purpose or goal, where the participants are committed and interdependent and work in a common context, physically co-located and using shared resources". Collaboration is a process by which individuals and/or groups work together on a practical endeavor. Collaborative working is a fundamental feature of organizations and is increasingly being supported by technology [2]. As people often work with others and with the increasing importance of computers in our work and everyday lives, it is natural to expect computers to play an important role in facilitating collaborative working [3].

Electronic collaboration (e-collaboration) is the computer mediated process of two or more (dislocated) people working together on a common purpose or goal, where the participants are, on the one hand, committed and interdependent and, on the other, work in a common context using shared resources, which supported by (Web-based) electronic tools [4]. In short, the goal of any collaborative working is that each of the group members brings and contributes ideas and knowledge to the group and shares it with them in order to combine it into the final result. In engineering education, concepts taught through lectures are often complemented by lab experimentation. Students can observe phenomena that are often difficult to explain by written material. Furthermore, interactive experimentation on real world improves the motivation of the students and also develops an engineering approach to solve realistic problems.

Many universities nowadays offer off-campus and distance learning programs such that the lab equipment or instruments are geographically located away from the student. The need to increase a collaborative learning in engineering education by means of delivering experimental data to people in different parts of the world has become a priority among students. Methods such as email do provide such a facility but they lack the ability to provide this data in a real time environment. Therefore, it is necessary to probe other approaches such as chat tools to provide data in a real time. Without collaboration, many computer users have felt introversive and isolated, but as in any human community, there is also controversy and slander. In a collaborative environment, goals of collaboration are to allow two or more students in conjunction with a tutor to communicate with each other at the same time, where they are distributed in space. Before beginning to discuss how we can improve and develop the field of collaborative working e-learning, it was very necessary to study and analyze other socio-technical systems, where collaboration is successfully realized such as air traffic control systems [1], team-oriented military systems [5], chat tools [6], and, last but not least, share desktop and share applications [7].

Complex problem solving tasks without instructional support will often demand too much from the students and will lead to ineffective learning. As long as students need instructions and help in solving scientific problems, the learning environment must provide knowledge for solving these problems. Instructional support is an important element especially in Web-based learning settings; therefore, remote labs should provide support for students. In remote labs, a tele-tutor communicates via synchronous or asynchronous communication tools with his students, resulting as a central role regarding instructional support. One form of communication between students and tutors is asynchronous; this kind of communication has several disadvantages [8]. First, students will not get any support from the tutor during the lab session; therefore, students might not able to find answers and solutions for their questions and problems in the experiment. Second, students have to accept time delays for getting answers to their questions, and therefore, if time delays are too long, they could lose their motivations. By contrast, the synchronous communication bypasses the above mentioned problems in such a way that, on the one hand, the synchronous communication restricts the time flexibility of the students and, on the other, upcoming problems can then be solved immediately by using chat tools and rule-based approach. 
Hands-on lab enables the students to discuss problems, where each student complements the other to achieve solutions easily. Although remote e-labs have several advantages, distributed labs including these with collaborative characteristics suffer from some problems such as [9] inequality in task division between students, students feel isolated because of lack of feed-back from other students, and groups without supervision will face a lot of difficult problems left unsolved. According to previous studies, the majority of current existing real labs are not constructed to allow the participants to collaborate in real time and are not designed to support students through an automated help in any time [10].

From this point, our contribution in this research will be about the development of education through the use of distributed e-labs for collaborative working; so after our previous discussion, the main problem caused by the asynchronous approach is that if the student groups are not under enough control by their teachers, they could have a time delay for getting the answers to their questions. Once the delay becomes too long, the students could lose their motivation, and could face many problems left unsolved. One way the discussed problems can be solved is by making a remote human tutor to support students available over a distance via synchronous communication tools, such as chat tools that allows quicker assistance. However, a remote human tutor cannot support students at any time and will not be available throughout the day. Therefore, it was intended to implement an automated helping system in the form of a rule-based e-tutor for user support in remote experiment environments. A rule-based system embraces a rule-base including stored knowledge about the correct experiment configuration. The rules determine what should be done in different situations and are initially designed by a human experiment, where each rule has two parts: conditions and action.

This contribution presents a collaborative working environment for a remote lab. Students have access to the remote lab via Internet from anywhere at any time. The collaborative environment allows the experimentation in a team, where the group is able to interact and to discuss the results of their work. The implementation of the developed e-lab was possible after having suggested a wellknown architectural model, the client-server architecture, which fits into the designing of collaborative working elearning environments [11]. It facilitates what is called multi-user e-learning environment, where more than one student and a tutor have access to an experiment at the same time and from different places. During an experiment, collaborated students are not only supported by a human tutor, but by a rule-based e-tutor as well. One widely used technique to establish the synchronous communication in our collaborative working environment is chat tools in addition to visualization techniques; they make it possible to establish an effective interaction between students and tutor.

Hence, after we have implemented a proposed architecture to support collaborative working, the objectives we had are providing the students with an automated help at any time, putting students in a real environment lab, distinguishing students' contributions from each other, targeting the system at a real interaction between students and tutor, and accessing the lab from any place and at any time.

\section{COLLABORATIVE WORKING ENVIRONMENTS}

Before we begin to establish and development of the collaborative working of the e-lab, it is necessary to study and analyze the technical systems in various social fields, and benefit the study of these systems, in terms of means of collaboration such as coordination and communication between the collaborators, etc.; however, collaboration is successfully in many fields, for example, airport control towers [1] with the major functionality to provide information and instructions, in the form of clearances, to aircrafts in certain areas of the airport and airspaces immediately around it for ensuring the safe and efficient movement of traffic. In the tower control room as common information space, the most of the collaborative works take place as follows. The tower controller is responsible for controlling aircraft on the runway. The ground controller is responsible for certain other areas of the airport. The planner (or coordinator) typically maintains contact, by telephone, with other air traffic control facilities that manage the airspace around the airport. Communication between different parts of the airport is achieved through the radar screen showing traffic in the region of airspace surrounding the airport. Coordination is also clear from the collection of flight strips indicating information about departing flights are relayed by a closed-circuit television link to the offices that providing services in the airport. In other words, it is clear that the activity of the airport is a highly distributed activity. Another example is team military systems [5], in which advanced technologies are used to facilitate military team work collaboration through communication and information exchange for enabling remote operations. Collaborative technologies currently used in remote military operations, such as email, and desktop conferencing, assist explicit communications between distributed team members around the world as part of physically distributed teams. Through chat tools [12], millions of people meet online to chat, to find like-minded people, to debate topical issues, to play games, to give or ask for information, to find support, to shop, or just to coupling with others. They go to chat rooms, discussion groups to participate by sending short messages in the form of text, as commonly used in the world. The system provides a chat facility students can use to communicate in real time with each other. The chat of every course provides students with a generic channel on which they can talk together. Beside the conversation space, a list of the users currently on the channel is shown. It is to note, that chat tools are an integral part of many collaborative environments as they mostly sample instant messenger and allow chatting with all participants. As a last example is share desktops and share applications [7]. A share desktop displays what you see on your desktop to all other participants and can both give control to others and take back control. Whereas share applications in addition to their ability to allow participants to see your application on their screen, they make it possible for a participant to control someone's application such as PowerPoint and Word. In other words, other participants can make their own edits and updates. Principles and techniques suggested in share desktop and share applications have been successfully applied in Web conferencing. The previous examples show that the shared features for any system supporting collaborative working are communication between partners, coordination of roles and task attributions, and production representing the task itself. 


\section{THE STATE-OF-THE-ART E-LABS}

Engineering courses normally include the lab components, which are essential to the learning process. Where using technology and the Internet could be for real labs or simulated labs to enhance the learning/lab concept and theory, a remote lab is suitable for engineering courses offered within distance learning and real lab environment. It differs from simulation approach which employs programming code to simulate the result of the lab experiment such as Pspice, Electronic Work Bench and LabVIEW.

Distance learning has taken on many forms and meanings. Early techniques for distance learning involved printed materials, including tutorials, assignments, and exams, passed between student and educators through the mail in order to complete course. Over time, this experience was enhanced through the use of other media including radios, television, audio and video tapes, and the telephone. Current practices are incorporating the Internet to bring multimedia interaction to students everywhere, anytime, in real time [13].

The Internet has become a widespread tool for teaching and learning because of the facts that it enables more flexible delivery (anytime), distance education (anyplace), new visualization possibilities (interactivity), and cost reduction. The Internet becomes increasingly important as a learning environment, and Internet-based technology is rapidly being adopted in engineering education as a tool for enhancing the educational experience enabling access to remote labs and performing real experiments.

There are several studies comparing the different philosophies and technologies used in contemporary remote labs [14]. Others concentrate on trends in remote labs [15]. The recent trends and advancements in technology show that there is a need user-friendly environment to increase the efficiency of the learn process. The basic problem faced by the engineering student during the lab classes is that they have to perform the experiments in the lab in a group of three or four students. Such as normally gives negative support to some of the students and hence create a lack of interest. In order to rectify such problems students try to copy the results of their batch mates which degrades the student's performance. Such problems can be rectified if the student is allowed to perform the experiments throughout the day by either being physically present in the lab or by performing the experiments via Internet [16]. Educators create these online labs to help students acquire hands-on lab experience without requiring physical access to a building with specific experimental equipment. Remote and virtual labs are two effective techniques for the use of the Internet in engineering education, previously introduced as computer-assisted instruction and computer-assisted experimenting. Specifically, the software involved in creating such online labs either allows a user to interact with an experimental setup located in another geographical location, i.e. a remote lab, or uses numerical simulation tools to emulate the behavior of experimental system, i.e. a virtual lab [17]. R-labs offer remote access to real lab equipment and instruments in real time [18]. It is the experiment/lab which is conducted and controlled remotely through the Internet. The experiments use the real components or instrumentation at a different location from where it is controlled or conducted. In brief, R-labs are the realness of systems learners work on. On the contrary, V-labs are based on simulations of real systems [19]. Where a simulation commonly replaces the real system, virtual labs typically resort to simulation software such as Matlab [20] or LabVIEW [21] or specific applications. These simulations can be run directly on a client host such as with Easy Java Simulation, but we could envisage server-side simulations when specific software or calculus power is required and not easily available on client side. The main drawback is that it is not a real system, but it is a relatively realistic model of a real system. We can find both remote or virtual lab experiments in various scientific and technical topics such as automatic control [22], electronics, chemicals and mechanicals [23], [24], and in robotics [25].

\section{ELECTRONIC COLLABORATION}

As people often work with others and with the increasing importance of computers in our work and everyday lives, it is natural to expect computers to play an important role in facilitating collaborative working [3]. Electronic collaboration (e-Collaboration) is the computer mediated process of two or more (dislocated) people working together on a common purpose or goal, where the participants are, on the one hand, committed and interdependent and, on the other, work in a common context using shared resources, which is supported by (Web-based) electronic tools [26]. We can set the goals of any collaborative working as:

- The group members each bring knowledge to the group.

- Share that knowledge between them.

- Each person can contribute ideas and desired work to be combined into a final result.

In engineering education, concepts taught through lectures are often complemented by lab experimentation. Students can observe phenomena that are often difficult to explain by written material. It is worth mentioning that collaborative learning in engineering education is of great significance because of the following reasons. First, students acquire various skills, such as the ability to work in teams and to achieve objectives in collaboration with others. Second, students learn to communicate with each other using technical expressions that are specific of their professional engineering domain. Third, students learn to integrate the know-how of others in order to accomplish a given work task. Fourth, students acquire remote collaboration skills, when the teamwork is carried out from several locations.

Interactive experimentation on real world improves the motivation of the students and also develops an engineering approach to solve realistic problems. A collaborative environment must allow the experimentation in a team, where the group is able to interact and to discuss the results of their work.

\section{DEFINITION, SOCIAL AND PSYCHOLOGICAL ASPECTS OF COLLABORATIVE LEARNING}

Collaboration between learners can have a positive impact in a learning session only if learners can exchange efficiently. Discussions and advices given by a co-learner are good means to help a learner in knowledge understanding. Web-based collaborative environments are a special category of e-learning tools that support a group of 
PAPER

A REMOTE ENGINEERING LAB FOR COLLABORATIVE EXPERIMENTATION

learners in achieving a common learning goal. In local lab experiment, students usually work together in groups of two or more. This learning paradigm is often called collaborative learning. Collaborative learning develops skills for solving problems in a team. The premise of collaborative learning is based upon consensus building through collaboration by group members. Members of the learning group will usually organize their activities themselves and decide upon the roles of the different members via consultation and negotiation. With the rapid expansion and availability of communication and information technologies, collaborative learning can also be done effectively in a remote environment at different places. Collaborative working environments bring together users, which are geographically distributed, but connected via a network [27]. Different social and psychological aspects deal with collaboration in learning processes [28]:

- Cognitive Learning: Learning produces sustainable results when external information or the requirements of a task can be embedded in already existing cognitive structure. In other words, it must serve as confirmation, modification or contradiction of the learner's existing knowledge. It is to note that cognitive science is an interdisciplinary science that draws on many fields such as psychology, artificial intelligence, linguistics, and philosophy that are combined together to develop theories about human perception, thinking, and learning.

- Motivation: The learning process will be better accepted and will lead to sustainable knowledge when learning can be experienced as the result of one's own activity, not as a mere adaptation to the knowledge of other people.

- Social construction: The construction of the three social elements: understanding, knowledge acquisition and production are mainly based on collaborative knowledge-sharing interaction with others.

\section{LEARNING WITH INSTRUCTIONAL SUPPORT}

Complex problem solving tasks without instructional support will often demand too much from the students and will lead to ineffective learning. The ability to engage in two-way communication with an instructor and other learners allows distance learners in facilitated courses to solve in more complex learning problems. As long as students need instructions and help in solving scientific problems, the learning environment shall provide knowledge for solving these problems. Instructional support is an important element especially in problem-based learning settings; therefore, remote labs must provide support for students.

In remote labs, a tele-tutor communicates via synchronous or asynchronous communication tools with his students, resulting as a central role regarding instructional support. The Web makes it possible to integrate synchronous and asynchronous technologies so that students can benefit from both. These combinations of technologies and the Web site provide a richer basis for collaborative course. However, technologies choices must ensure that all students will be able to use these technologies, and that software is straightforward and pleasant to use [30].

\section{A. Asynchronous courses}

In courses that are delivered asynchronously, learners can each make use of the communications medium at a time and place most convenient to them; because of this, these courses are available to others who have difficulty scheduling attendance in traditional classroom environments. In addition, asynchronous classes can be easily made available to a collaborative learning of learners who can share information and experiences with one another without regard to geographic boundaries or time limitations. In the simplest configurations, asynchronous courses can make use of extremely communications media such as e-mail. Some instructors and learners are not suitable to collaborate in asynchronous interactions. For one thing, asynchronous communications are largely text-based, which can limit the effectiveness of discussions delivered through this medium. Students who are not native speakers of the language used for course delivery face not only special difficulties, but cultural and language barriers can more easily lead to miscommunication and misunderstandings in text-based communications [29].

\section{B. Synchronous courses}

Synchronous courses that employ two-way video or audio technologies can allow instructors and learners to collaborate demonstration and observation of practices for a variety of skills-based learning activities in a way that it would not be possible in other forms of distance classes because of the fact that teachers and learners can engage in nearly all traditional learning activities through voice, text, and video. In these instances, the online classroom can begin to seem more like a traditional classroom in many respects, and teachers can begin to employ many of the same approaches used to teach face-to-face classes, as well as being able to respond to visual and verbal forms from students [31].

\section{DISTRIBUTED SYSTEM ARCHITECTURE AS A BASIS FOR E-COLLABORATIVE REMOTE ENGINEERING LABS}

\section{A. Introduction}

Remote lab can be considered as a well-established teaching structure and learning environment for developing skills required for the efficient collaborative learning environment to achieve collaboration and communication between students [32]. The concept of the learning services and their deployment through technologies are excellent means to integrate real lab into collaborative elearning environments for engineering education [33]. This chapter describes in-depth a suggested architecture based on .NET technologies to support the software development process of Web-based collaborative working environment, in addition to an interactive graphical userinterface (GUI) environment. This GUI facilitates the remote control and access of various instruments and experiment setups.

Our proposals have emphasized on the collaboration aspects between two students or more. Collaboration can be achieved when students work together. It will be shown how we have implemented an e-collaborative environment for remote experimentation supplemented by a rule-based e-tutor, based on Microsoft Visual Basic 2010 .NET framework [34] that gives support in order to facilitate the implementation of the Web-based collaborative 
working. A suggested architecture can be built around an existing lab components and equipment in a general university/ engineering college without much difficulty. It is required to design an experiment set-up and to write software control code for interfacing it with both a lab server and the Internet. It was necessary to program controls to interface our experiment with the lab server and the Internet. The lab experiment set-up is attached to a server, which provides the Web interface to the remote clients. Multiple clients are able to get connected through remote login into the system.

It is undeniable that programming libraries included in visual programming environments that are used to create windows applications are more powerful to its corresponding Web-based tools, that is, it will be easier to create powerful user-interfaces for virtual instrumentations and remote monitoring of remotely located technical systems such as production processes or remote labs that resemble the reality as much as possible. To this end, this allows the student to move seamlessly from virtual representations of test equipment in a remote lab environment to actual test equipment in a real lab and to be capable of using this equipment competently as a direct result of their online experiences [35]. Fortunately, Visual Studio 2010 allows developers to create user-interfaces with the desired features previously mentioned in the form of a window application, and, in a further step, to transform with a few instructions to a Web-based one. All that is needed is to build the windows control library, take the resulting dynamic link library (dll) and placing it in root of your Web based application and then add the following line of code to the source of your Web page:

$<$ object id="myName" classid = "http: WindowsControlLibrary1.dll\#WindowsControlLibrary1.UserControl1" height $=" 469 "$ width $=" 702 "><$ lobject $>$

\section{B. System structure for collaborative working}

System that was designed, developed and implemented for the purpose of remote access to lab equipment and to enable experimental collaborative work for on-line support of e-learning is called e-collaborative environment for remote experimentation. It is a prototype system that is intended to support experiments in the area of electronics, but its structure poses no limitations on other types of experiments also, such as in physics, mechanical engineering, or some similar fields of engineering or science. The purpose of the work described in this research was to consider the ability to provide a remote collaborative learning facility via an Internet link as an alternative approach for the course delivery. In this case, electronic circuit arrangement hardware was modified for connection to a remote collaborative lab.

In lab experiments of the faculty of engineering, solving tasks without instructional support will often demand too much from the students and will lead to ineffective learning. As long as students need instructions and help in solving scientific problems, the learning environment shall provide knowledge for solving these problems. Instructional support is an important element especially in problem-based learning settings; therefore, a remote lab should provide support for students. In the remote lab, a tele-tutor communicates via synchronous or asynchronous communication tools with his students, resulting as a central role regarding instructional support. An automated helping system is implemented in the form of a rule-based e-tutor for user support in complex remote experiment environments. A rule-based system embraces a rule-base including stored knowledge about the correct experiment configuration. Doing so, we have found the solution to the problem of supervision of the instructor to give feedback directly to students, as well as provision of dialog box text messages to be feedback to the students who did not find any information feedback from the other students. In order to solve the problem inequality in task division between students color coding was used.

\section{Distributed system architecture for collaborative e- learning}

The architecture applied to this system follows the simplest client-server architecture, where an application is organized as a server and a set of clients. Figure 1 illustrates the system architecture accommodated to the special needs of this research for establishing a collaborative working e-learning environment, which is not only supported by a human tutor, but by a rule-based e-tutor as well. This architecture enables the different users such as students and tutors to carry out the following activities: performing on real (physical) experiments remotely whenever they want and anywhere they are, collaborating by two students or more and attribute the tasks between them, developing remote experiments and hardware facilities based on an existing course structure and requirements to facilitate the collaborative work remote learning scenario, establishing synchronous interaction between students and tutor, and providing the students with an automated help at any time.

This system is organized into subsystems and components. It also includes the end users of the system and the user-interfaces through which the users can interact with the system in order to complete tasks. In brief, overall decisions are made about actors /sub-systems interaction, data storage, and implementation.

Hardware Architecture: The remote users (collaborators) can login to the e-collaborative server using TCP/IP link over the Internet and can select and perform an experiment. At the server end, hardware setup of all the lab instruments and the experiments are attached to the server, instruments and devices are also connected with the programmable instruments through a PCI General Purpose Interface Bus (GPIB) card and GPIB cables. An experimental board containing different components and electronic elements are connected to the parallel port of the server to view real-time experimental setup.

Software Architecture: The software design for the ecollaborative environment for remote experimentation system focuses on a client-server software model whose primary functionality is to interface the remote users (collaborators) with the server and controlling of the actual lab experiments / instruments. The GUI for the client side has been developed using Microsoft Visual Basic VB.NET. The underlying protocol for communication between server and client side is TCP/IP. The server side controls the server process as well as modifies the configurations of the instruments. It handles all the tasks of communication to and from the instruments using the instrument controller, namely a PCI GPIB card. Standard command for language library has been used in vb.net environment to send commands to and receive data from the instrument driver, which uses the GPIB IEEE 488.2 standard protocol to drive the instruments. 
The clients' side control the experiment interface by sending command to the parallel port for selection of different points related to the experiment board. The client side GUI allows the student to control various functions of the instruments associated with the experiment in realtime. For each instrument as well as experiment at the server end, corresponding GUI has been designed at the client end using vb.net control toolbox. The client's command generator for instrument issues commands according to the parameter set specified by the student for a particular instrument and transmits them to the server. The experiment results checked by e-tutor then sent back by the server are then handled and displayed in the client GUI. The architecture proposes that our distributed application should be made of the following components.

Web server and Web-based user-interface: The Web server provides several services for the clients through a Web browser. In addition to its role as a middleware to communicate with the clients and the other system components via the Internet, it represents the central unit of the collaborative e-learning and functions as a coordinator between the various components. All clients of the distributed e-collaborative system, students and tutors, use the same Web-interface. In our case, the clients will be mediated by a conventional Web browser such as the Microsoft Internet Explorer. When the Web-based user interfaces were designed, several human-computer interaction rules for user-interface design had to be taken into account such as consistency of data display such as labeling and graphic conventions, minimal memory load on user, flexibility for user control of data display, presentation of information graphically where appropriate, standardized abbreviations, presentation of digital values only where knowledge of numerical value is necessary and useful, minimal surprise, user guidance, that is, the interface should provide meaningful feedback when errors occur and provide user help facilities, user familiarity meaning that the interface should use terms and concepts drawn from the experience of the people who will make most use of the system [36].

Rule-based e-tutor: Main goal of this research is helping students to execute experiments remotely at any time and from anywhere. This goal can be fulfilled when the synchronous human tutor is continually available. Realis-

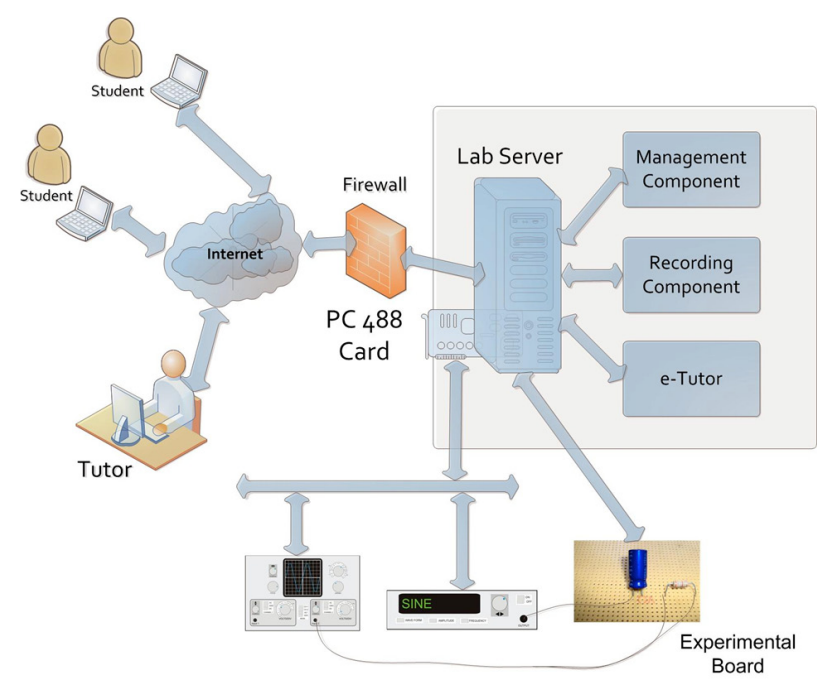

Figure 1. Distributed system architecture of the e-collaborative environment for remote experimentation tically, a remote human tutor will not be online all day. Therefore, we want to implement an automated help system (e-tutor) for user support in complex remote experiment environments. Hayes-Roth [37] notes that rule-based systems automate problem-solving know-how and providing a means for capturing human expertise. In our research, the e-tutor is realized as a simplified rule-based system because our focus is mainly on collaborative systems and not on knowledge-based systems. Knowledgebased systems, which represent an important class of intelligent systems, can be especially useful for solving complex problems in cases where purely algorithmic or mathematical solutions are either unknown or demonstrably inefficient.

Recording component: It is important to have a component that records the students' interactions with the userinterface. The importance of this component includes the following. First, storing the work of each student during the course of the experiment, and storage to be corrected by the teacher and whether the connection is true or not. Second, if the instructor was not found on-line and the etutor could not correct the connections of the students through the experiment, sometimes the human tutor is an assessment or correction after the students had finished their work, for this reason we have a need for recording of experiment at work. Third, it can also record the experiment as a video and store it in the format "Movi file", which would be beneficial to students for reference when needed.

The experiment: The remote experiment can be any one of an engineering lab covering topic related to electric circuits or electronics and so on. Fortunately, most of the current instrumentations such as oscilloscopes and multimeters are provided with control through PCI GPIB (General Purpose Interface Bus) card and GPIB cable [38].

\section{User-Interface design for remotely collaborating students}

Before discussing the Web-based user-interface for the clients, it will be of great significance if we clarify some term definitions related to human factors that must be taken into account when we have designed the user-interface. The prototype is the basis for a Web-based user-interface for the clients: the students and the tutor. Ergonomically, we have to distinguish between aspects of perceptive and cognitive ergonomics [39]. The cognitive ergonomics relates to reasoning, memory, and knowledge [40]. Here, we are more concerned with perceptive ergonomics focusing on designing issues such as color, shape form, dimension and allocation, highlighting and so on. The desktop of the Web-based user interface is divided into several windows for representing different functionalities. Some of these windows are the experiment and the chat tool window. The experiment window represents the remote tool kit and the instrumentation necessary for that experiment, which will be virtually visualized. The instrumentation area includes the equipment such as oscilloscopes to pursue the signals after building the circuit; as well as various function generators to feed the circuit with input signals. The students are able to connect the inputs and outputs of a virtual oscilloscope with other electronic elements. After every building step the students can select the accept button, the user-interface sends the circuit configuration to the server, where the e-tutor initially carries out a consistence check to the sent circuit data. If these 
data passes the check, this data is used to control the real experiment. The chat tool window provides our system with a chat tool which stimulates collaboration among students while executing an experiment. After starting the chat application in our implementation, a Web page based on "aspx" technology will be started, which appears once a student clicks either the continue button. After that, the student enters her/his name to be used in conversations between students. By means of the chat-text window, a student can send a text message to a particular student or to all students at once.

\section{E. Circuit-wiring electronics}

The normal procedure for performing a single experiment includes the following steps [41]. First, every student team wires the circuit specified in the instruction manual using a voltage source, the breadboard, and some of the components provided. At least one of the instruments must be connected to test points in the circuit in order to collect experimental data. Second, the instructor checks each circuit formed to avoid possible damage. If the circuit is safe, the student team is allowed to continue by activating the source. Once the source is activated, they begin to deliver the required experiment. Third, the students read the instruments. A snapshot during an experiment using the remote lab configuration is shown in Figure 2. A type of circuit-wiring, e.g., a switching point must be used.

\section{DISCUSSION}

Lab experiments are vital and cannot be separated from science and engineering education. In most cases, students were and still are coming to the lab to test the theory they learnt during lectures or had gained from different knowledge sources. In most cases, they work in groups and, ideally, they learn how to collaborate as a team. In some cases, they just follow instructions from their supervisors. Collaboration in a remote lab, which allows more students to work simultaneously, can be very similar to the real one except that one entity could be missing; namely, the supervisor might not be on hand. However in some cases, the supervisor's help is still available via the communication channel. There are several benefits achieved through introducing distributed collaborative elearning systems. First, students can perform on real (physical) experiments remotely whenever they want and from anywhere. Second, two students or more supported by an experiment tutor are enabled to collaborate together, leading to facilitate the collaborative work of the remote learning scenario. Third, synchronous interaction between students and tutor is possible. Fourth, students are always provided with an intelligent automated help.

One of the problems faced by engineering students during the lab classes is that they have to perform the experiments in the lab in groups of three or four students. This sometimes gives negative support to some of the students, inequality in task division between them, and hence creates a lack of interest. In order to rectify such problems, students try to copy the results of their batch mates what might degrade the student's performance. Demonstrating a difficult concept to a learner who is having trouble understanding in traditional classroom, the instructor can adapt materials to meet individual student needs, so that flaws and deficiencies in both course design and the instructional materials used to support teaching can usually

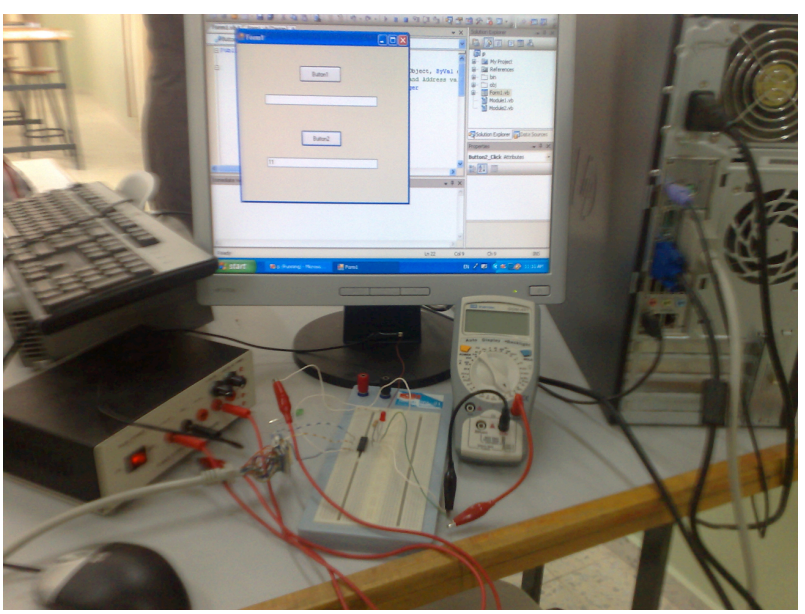

Figure 2. The remote lab configuration

be compensated. Sometimes, if the number of students in the classroom is large, there is no opportunity to answer all questions and queries from asked by the students to their instructor; therefore, students do not receive feedback from their instructor. All the problems we have talked about previously do not only occur within the traditional classroom, but also occur in e-labs for collaborative working as well. Such problems we have addressed so far can be rectified if the students are allowed to perform the experiments throughout the day via the Internet. These online labs help students to acquire experience achieved by conventional hands-on labs, but requiring a physical access to a building. Therefore, we have proposed in this research distributed system architecture for collaborative e-learning.

While having explored and experimented collaborative working environments for remote experimentation, we found that it was necessary to consider other collaborative systems successfully applied in other fields such as air traffic and the military. This architecture puts students in a real environment for manipulating their experiments via the Internet. Our distributed e-collaborative system could be made of the following components: a server, Webbased user-interfaces, a management component, a rulebased system (e-tutor), a recording component, and the experiment itself. The Web-based user-interfaces play a central role within the distributed e-collaborative system as it represents the window to the experiment. Their design takes various human-computer interaction rules for user interface into account. The Web-based interface, which is realized as an integrated desktop, includes windows for displaying the experiment, a chat tool, a window for active users, and a dialog frame for session control.

In an e-lab, the interaction between instructor and students are indirect and the communication between them takes place through any form of media. Therefore, we proposed the use of a chat tool, which was implemented in vb.net for allowing effective interaction between students and instructor as it is the case in real environments. Due to this, the students can receive feedback or any assistance needed, sampling studying in traditional classrooms. Since a remote human tutor can't be online every time to support students, it was necessary to implement an automated helping system (e-tutor) to support students, and to provide a feedback to them when they need clarification on their work. In this research, the e-tutor is realized as 
PAPER

A REMOTE ENGINEERING LAB FOR COLLABORATIVE EXPERIMENTATION

TABLE I.

A COMPARISON BETWEEN OUR RESEARCH CONTRIBUTIONS WITH OTHER COLLABORATIVE E-LABS

\begin{tabular}{|c|c|c|c|c|c|}
\hline Property & $\begin{array}{l}\text { Automated help } \\
\text { (e-tutor) }\end{array}$ & Share desktop & $\begin{array}{l}\text { Coordination } \\
\text { (roles attribution) }\end{array}$ & $\begin{array}{l}\text { Synchronous/ Asynchro- } \\
\text { nous Communication }\end{array}$ & Real/Virtual Environment lab \\
\hline$[10]$ & none & none & none & $\begin{array}{l}\text { Synchronous } \\
\text { (chat tool) }\end{array}$ & Virtual (Simulation results) \\
\hline [27] & none & none & none & Asynchronous & Virtual (Simulation results) \\
\hline [33] & none & none & none & $\begin{array}{l}\text { Synchronous } \\
\text { (chat tool \& video } \\
\text { conference) }\end{array}$ & Virtual (Simulation results) \\
\hline Our distribution & Rule-based e-tutor & Available "logmein" & Color coding & $\begin{array}{l}\text { Synchronous } \\
\text { (chat tool) }\end{array}$ & Real results \\
\hline
\end{tabular}

TABLE II.

DIFFERENCES BETWEEN CONVENTIONAL COLLABORATIVE AND INTERNET-BASED E-COLLABORATIVE LEARNING ENVIRONMENTS

\begin{tabular}{ll}
\hline $\begin{array}{l}\text { Conventional collaborative } \\
\text { environments }\end{array}$ & $\begin{array}{l}\text { E-collaborative learning envi- } \\
\text { ronments }\end{array}$ \\
\hline $\begin{array}{l}\text { Instructor-centered } \\
\text { Lecture-oriented }\end{array}$ & $\begin{array}{l}\text { Learner-centered } \\
\text { Collaborative and discussion-based }\end{array}$ \\
While teachers act as experts, & $\begin{array}{l}\text { Student participates in team learning } \\
\text { through learning from other learners } \\
\text { students are perceived as } \\
\text { novices }\end{array}$ \\
$\begin{array}{l}\text { Learning content is static } \\
\text { to create the learning process }\end{array}$ \\
$\begin{array}{l}\text { Emphasis is focused on eval- } \\
\text { uation and testing }\end{array}$ & $\begin{array}{l}\text { Emphasis is focused on perfor- } \\
\text { mance }\end{array}$ \\
\hline \hline
\end{tabular}

simplified rule-based system because our focus is mainly on collaborative systems and not on knowledge-based systems. The rules of the rule-based system consist of two parts: conditions and action. The e-tutor functions as an observer for students' actions manipulated on the experiment. Once the connections of the electronic elements on the virtual experiment are incorrect, the e-tutor displays a warning message and prevents contacting elements to be connected on the remote experiment board. According to previous studies, the majority of current existing real labs for collaborative working are not constructed to allow the participants to collaborate in real time and are not designed to support students through an automated help at any time [10], [33]. Table 1 demonstrates a comparison between the methodologies and techniques of other collaborative e-labs compared with our research contribution, showing the advantages and disadvantages of each philosophy.

Concluding that for collaborative e-learning systems, the synchronous approach is superior to the asynchronous one regarding instructional support. Table II shows the differences between the conventional collaborative and Internet-based e-collaborative learning environments. Concluding that for collaborative e-learning systems, the synchronous approach is superior to the asynchronous one regarding instructional support.

Table II shows the differences between the conventional collaborative and Internet-based e-collaborative learning environments.

\section{CONCLUSION}

It would be interesting if we can test our ideas with more complicated experiments. Complicated engineering experiments with many electronic devices and equipment can be easily implemented through scaling by adding new programmable devices, electronic components and PCs. One way the complexity of experiments can be reduced is the usage of programmable devices, which can manage a large number of experiments. For new experiments, new programmable devices must be installed and used. It would be of great interest to measure how the introduction of complex experiments affects the interaction between students, the human tutor, and the system; as well as whether the feedback returned from the simplified rulebased e-tutor to the students is satisfied and correct according to their mistakes manipulated on complex experiment circuits. Another problem that might appear through monitoring of complicated experiments is the clearness regarding inequality in task division between students that has been solved by means of color coding. Accordingly, a better version of the e-tutor based on knowledge-based techniques could be implemented to serve as an automated help system for user support in complex remote experimentation environments.

\section{REFERENCES}

[1] M. Light, M. Bell and M. Halpern, What is Collaboration? Virtual Team Success Factors, Commentary COM-14=4302, Gartner Inc. 2001.

[2] M. W. L. Fong, e-collaboration and virtual organizations, Victoria University, Australia, Copyright (C) 2005 by IRM Press, ISBN 1-59140-285-9. M. W. L. Fong, e-collaboration and virtual organizations, Victoria University, Australia, Copyright (C) 2005 by IRM Press, ISBN 1-59140-285-9.

[3] J. Begole, M. Beth Rosson, and C. A. Shaffer, "Flexible Collaboration Transparency: Supporting Worker Independence in Replicated Application-Sharing Systems," ACM Transactions on Computer-Human Interaction, vol. 6, no. 2, pp. 95-132, 1999. http://dx.doi.org/10.1145/319091.319096

[4] M. W. L. Fong, e-collaboration and virtual organizations, Victoria University, Australia, Copyright (C) 2005 by IRM Press, ISBN 1-59140-285-9.

[5] S. D. Scott, M.L. Cummings, D.A. Graeber, W.T. Nelson, R.S. Bolia, "Collaboration Technology in Military Team Operations: Lessons Learned from the Corporate Domain," Proceedings of CCRTS 2006: the Command and Control Research and Technology Symposium, San Diego, CA, USA, 2006.

[6] "Collaborative Tool Demonstration," Peace and stability education, Workshop report, the United States Army Peacekeeping and Stability Operations Institute at Carlisle Barracks, Pennsylvania, USA, pp. 189-205, 2006.

[7] Y. Cao, G. Sharifi, Y. Upadrashta, J. Vassileva, "A Case Study on Social Network in a Computer Game," Proceedings of the second international joint conference on Autonomous agents and multiagent systems, Melbourne, Australia, pp. 954 - 955, 2003. http://dx.doi.org/10.1145/860575.860742

[8] A. Böhne, N. Faltin, B. Wagner, "Synchronous tele-tutorial support in a remote laboratory for process control," INNOVATIONS 2004: World Innovations in Engineering Education and Research, edited by W. Aung, R. Altenkirch, T. Cermak, R. W. King, L. M. Sanchez Ruiz, iNEER, USA, 2004. 
[9] O. C. Santos, A. Rodríguez, E. Gaudioso. J. G. Boticario, "Helping the tutor to manage a collaborative task in a web-based learning environment," $11^{\text {th }}$ international conference on artificial intelligence in education, Sydney, Australia, 2003.

[10] M. J. Callaghan, J. Harkin, T. M. McGinnity, L. P. Maguire, "Client-Server Architecture for Collaborative Lecture-Led Remote Experimentation," $7^{\text {th }}$ Distance Learning and the Internet Conference APRU DLI 2006, Japan, 2006.

[11] M. Cefalo, L. Lanari, G. Oriolo, M. Vendittelli, "The REAL Lab: Remote experiments for active learning," XLI AICA Annual Congress, Trento, IT, 2003.

[12] J. Lonchamp, "A Structured Chat Framework for Distributed Educational Settings," 6th International Conference on Computer Supported Collaborative Learning - CSCL'05, Taipeh, Taiwan, 2005.

[13] A. Leleve, P. Prevot, H. Benmohamed, M. Benadi "Generic e-lab platforms and e-learning standards," 20 avenue Albert EINSTEIN, 69621 VILLEURBANNE Cedex, FRANCE (arnaud.leleve@insalyon.fr) Laboratoire ICTT - INSA de LYON.

[14] Z. Nedic, J. Machotka, A. Nafalski, "Remote laboratories versus virtual and real laboratories," Proc. Frontiers Educ. Conf., Nov. 5(8): 1 T3E-1-T3E-6, 2003.

[15] L. Gomes, S. Bogosyan, "Current Trends in Remote Laboratories," IEEE Trans. Ind. Elect., 56 (12): 4744-4756, 2009. http://dx.doi.org/10.1109/TIE.2009.2033293

[16] A. Taneja, A. Kushwah, A. Gupta, V. B Vats, "TeleLab-A Remote Monitoring and Control System," iJOE International Journal of Online Engineering, Vol. 3, Issue 1, 2007

[17] R. C. Almgren, J. A. Cahow, "Evolving Technologies and Trends for Innovative Online Delivery of Engineering Curriculum", iJOE International Journal of Online Engineering, Vol. 1, Issue 1, 2005.

[18] N. Aliane, "LABNET: A Remote Control Engineering Laboratory," Universidad Europea de Madrid, DACA, Madrid, 28671 (Spain), 17 November, 2006.

[19] P. Coquard, M. Guillemot, A. Leleve, D. Noterman, H. Benmohamed, "AIP-Primeca RAO Remote Laboratories in Automation," iJOE International Journal of Online Engineering, Vol. 4, Issue 1, February 2008.

[20] K. Zakova, M. Sedlak, "Remote Control of Experiments via Matlab, "Faculty of Electrical Engineering and Information Technology Slovak University of Technology, Bratislava, Slovakia, 18 July 2006.

[21] E. S. Brenner, "Virtual Instruments for the Circuit Analysis with Interactive Parameter Modification," iJOE International Journal of Online Engineering - www.i-joe.org, - Vol. 2, Issue 3, 2006.

[22] S. Uran, D. Hercog, K. Jezernik, "Remote Lab Experiment RC Oscillator for Learning of Control," iJOE International Journal of Online Engineering, Vol. 2, Issue 4, 2006.

[23] I. Gustavsson, J. Zackrisson, K. Nilsson, J. Garcia-Zubia, L. Hakansson, I. Claesson, T. Lago, "A Flexible Electronics Laboratory with Local and Remote Workbenches in a Grid," iJOE International Journal of Online Engineering, Vol. 4, Issue 2, May 2008.

[24] D. Geoffroy, T. Zimmer, M. Billaud,"A remote laboratory for electrical engineering education," iJOE International Journal of Online Engineering, Vol. 2, Issue 3, 2006.

[25] F. A. Candelas Herías, C. A. Jara Bravo, F. Torres Medina, "Flexible virtual and remote laboratory for teaching Robotics," Current Developments in Technology-Assisted Education (2006).

[26] T. Schümmer, S. Lukosch, Patterns for Computer-Mediated Interaction. John Wiley \& Sons Ltd, England, 2007.

[27] A. Bischoff and C. Röhrig, ,Web-based Environment for Collaborative Remote Experimentation," Proceedings of the 42nd IEEE Conference on Decision and Control Maui, Hawaii USA, December 2003, IEEE, pp. 2514- 2518
[28] R. Kuhlen, J. Griesbaum, T. Jiang, J. Konig, A. Lenich, P. Meier, T. Schütz and W. Semar, K3 - an e-Learning Forum with Elaborated Discourse Functions for Collaborative Knowledge Management. Department of Computer and Information Science, University of Konstanz, Germany

[29] Distance Learning for Nonprofit Organizations. NinthBridge, New York, 2003

[30] J. Preece and D. Maloney-Krichmar, Online Communities: Focusing on sociability and usability. University of Maryland, Baltimore County, USA, 2003

[31] A. Böhne, N. Faltin and B. Wagner, "Synchronous tele-tutorial support in a remote laboratory for process control," INNOVATIONS 2004: World Innovations in Engineering Education and Research (iNEER), W. Aung, R. Altenkirch, T. Cermak, R. W. King and L. M. Sanchez Ruiz, Eds. USA, 2004.

[32] J. Machotka, Z. Nedic, "From the Collaborative Environment of the Remote Laboratory NetLab to the Global Collaboration," University of South Australia, Adelaide, Australia, iJOE International Journal of Online Engineering, Vol. 4, Special Issue 1: REV2008, July 2008.

[33] C. Schmid, "Grid Technologies for Virtual Laboratories in Engineering Education," Ruhr-Universität Bochum, Bochum, Germany, iJOE International Journal of Online Engineering, Vol. 4, Issue 1, February 2008

[34] Deitel Associates, Visual Basic 2010: How to Program, Prentice Hall, 2011.

[35] M. J. Callaghan, J. Harkin, T. M. McGinnity, L. P. Maguire, "Client-server architecture for remote experimentation for embedded systems," International Journal of Online Engineering (iJOE), 2006, 2(4).

[36] B. Shneiderman, C. Plaisant, M. Cohen, and S. Jacobs, Designing the User Interface: Strategies for Effective Human-Computer Interaction. Pearson-Addison Wesley Longman, 2010.

[37] F. Hayes-Roth, "Rule-based systems," Communications of the ACM, vol. 28, Nr. 9, pp. 921-932, 1985. http://dx.doi.org/ $10.1145 / 4284.4286$

[38] A. J. Caristi. Ieee-488: General purpose instrumentation bus manual (professional and technical series), Academic Press, 1989.

[39] G. Johannsen. Mensch-Maschine-Systeme. Berlin: Springer, 1993. http://dx.doi.org/10.1007/978-3-642-46785-1

[40] J. R. Anderson, Cognitive psychology and its implications (5th ed.), New York: Worth, 2000.

[41] I. Gustavsson, Blekinge Institute of Technology, SE-372 25 Ronneby Sweden," Traditional laboratory exercises and remote experiments in electrical engineering Education," International Conference on Engineering Education, July 21-25, 2003, Valencia, Spain.

\section{AUTHORS}

Salaheddin Odeh is with the Department of Computer Engineering, Faculty of Engineering, Al-Quds University, Abu Deis, Jerusalem, Palestinian Territories. Email: sodeh@eng.alquds.edu

Eiman Ketaneh is with the Faculty of Information Technology, Al-Quds Open University, Tulkarm, Palestinian Territories. E-mail: eng.eiman@yahoo.com.

This article is an extended and modified version of a paper presented at the EDUCON2012 conference held at University Mohammed V Souissi, Morocco in the period 17-20 April 2012. Received 29 January 2013. Published as resubmitted by the authors 12 June 2013. 